\title{
La diáspora africana: entre fractura y diálogo intercultural en Argentina
}

The African Diaspora: between fracture and intercultural dialogue in Argentina

Ibrahim Tuo

Universidad Félix Houphouët Boigny Abidjan - Costa de Marfil

Abidjan, Costa de Marfil

ibrahim_tuo86@yahoo.com

\section{RESUMEN}

La diáspora africana de Argentina es una población étnica diferencial que históricamente ha sido víctima de exclusión estructural a partir de los discursos de la nación. Estos discursos y los diálogos interculturales han fracturado a la diáspora africana en el país de tal modo que han sido invisibles mucho tiempo. Con el fin de contextualizar la problemática que abarca esta tesis daremos a conocer ciertos discursos que han permitido la división, la separación y la invisibilización de la población de origen africano en el escenario nacional argentino. Esta investigación expone las experiencias vividas por la diáspora africana que se posiciona de forma crítica en el debate contemporáneo en Argentina.

Palabras clave: diáspora; África; dialogo; intercultural; Argentina

\begin{abstract}
The African Diaspora in Argentina is a differential ethnic population that has historically been a victim of structural exclusion from the discourses of the nation. Some forms of these discourses and intercultural dialogues have fractured the African Diaspora in the country in such a way that they have been invisible for a long time. To contextualize the problems covered by this thesis, we will present certain discourses that have divided, separated, and made invisible the population of African origin in the Argentine national scenario. This research exposes the experiences lived by the African Diaspora that are critically positioned in the contemporary debate in Argentina.
\end{abstract}

Keywords: Diaspora; Africa; dialogue; intercultural; Argentina 


\section{INTRODUCCIÓN}

En este trabajo abordaremos el campo de estudio sobre la diáspora africana en Argentina, a través de un diálogo entre autores que reflexionaron sobre las experiencias de esta diáspora como una parte de la sociedad fracturada. Podemos considerar el proceso de formación nacional de alteridad/identidad y el lugar de la diáspora africana en el imaginario social relativo a la hegemonía. Éste resalta de las continuidades y de las rupturas entre el proyecto de nación pensada a finales del siglo XIX y hasta ahora. Un ejemplo claro de este proyecto es el discurso de Aline Helg (1990) cuando ha publicado entre finales del siglo XIX y comienzo del siglo XX su estudio comparativo sobre las políticas raciales en Argentina y Cuba. En esta investigación, destaca que Argentina se ha convertido en un buen ejemplo que deben seguir las demás naciones latinoamericanas por su éxito en el proceso de blanqueamiento nacional llevado a cabo gracias a las políticas que favorecían la inmigración masiva de europeos y también por los procesos de marginación de la población negra y de exterminación de la población indígena.

Así, definimos la diáspora africana, como un concepto que se relaciona con la presencia africana en América o que ha surgido a partir de la llegada de los esclavos al continente americano, como una reflexión interna al movimiento africano, de donde también comenzó a pensarse en términos de criollo y de negritud, en la significación francesa del término. Según Brent Hayes Edwards, a diferencia de otros conceptos esencializantes de las identidades racializadas, el concepto de diáspora como negritud o panafricanismo es un concepto que tiene diferentes usos contextuales. Siguiendo al mismo autor es una idea de transnacionalidad, es decir que es una situación, una entidad, una institución, una norma jurídica o cuerpo legislativo que despliega efectos transfronterizos o más allá del marco puramente estatal y transculturalidad (El proceso transcultural enfatiza en el intercambio de dos culturas igualmente complejas en el proceso de creación de una nueva identidad cultural, ya sea, voluntaria o forzada) que se requiere para ser formulada también en relación con las cuestiones de poder, como por ejemplo las desigualdades, el racismo y las formaciones nacionales de la diferencia o de la alteridad (Edwards, 2001).

Tomando el contexto de Argentina, podemos decir que se configura como un espacio marginal de la diáspora africana y de las temáticas raciales dentro del debate de las Ciencias Sociales, particularmente en el estudio antropólogo. Se propone en este caso un estado de la cuestión de dichos estudios que se consideran como los principales trabajos que han tratado de normalizar a lo largo del siglo XX. Los actuales estudios afro-argentinos en Argentina se presentan como ricos en las investigaciones. Pero en cuanto a sus trayectorias de estudio, son poco problematizados. Siguiendo a María Elena Vela (2001, pp. 49-62) los múltiples trabajos que abordan los temas relacionados con la presencia africana en Argentina se conocen generalmente como "estudios afro-argentinos" y, estos son específicos sobre África y sus descendientes, si bien no se presentan como campos separados ni visiblemente definidos. A eso, Alejandro Frigerio añadía que se trata de un campo de estudios considerado limitado, escaso o pequeño en relación con la producción científica (Frigerio, 2008).

Este estudio se focalizará en los estudios sobre los discursos de fractura, de exclusión, de ilegalidad, y sobre todo del Estado, que ha sufrido la población descendiente de África en Argentina. El objetivo de esta investigación es demostrar cómo interactuaban los distintos discursos que tenía la población blanca y el Estado argentino frente a la población negra tales como el discurso de exclusión, de negación, de blanqueamiento, y de cultura.

\section{METODOLOGÍA}

Como punto de partida de esta investigación, hicimos un acercamiento de investigación y de descripción de los discursos de fractura hasta la invisibilidad. Luego, para tener una noción, nos hemos basado sobre muchos documentos escritos en este dominio. Finalmente, hemos utilizado 
como método el analítico para analizarlos y el cualitativo que es el método científico que nos ha permitido observar para recopilar datos. La amplia variedad de los autores principalmente fue considerada para conseguir hacer un estudio que abarque la fractura a partir de la totalidad de los discursos.

A continuación, mencionaremos los autores utilizados por ser los protagonistas de este artículo y para tener una noción de su caracterización. Como autores analizados tenemos: Edwards, 2001; Frigerio, 2008; Binayán Carmona, 1980; Yao, 2002; Geler, 2008a; Solomianski, 2003, Domínguez, 2004; Domenech, 2005 y muchos otros.

\section{DESARROLLO}

\section{1 llegalidad y fractura de la diáspora}

Para entender mejor los estudios sobre la identidad en Argentina hoy en día tenemos que ligarlos a la esclavitud que es el fruto de desigualdad y de división entre los descendientes africanos y los colonizadores. Este país ha sido presentado como un ejemplo excepcional de triunfo de la cultura europea en el sur del continente. Fue un fenómeno que empezaba a difundirse al inicio de la consolidación del estado nacional. A partir de este momento empezará la división y la fractura de un pueblo. Así dicho, apareció en Argentina como en todo América lo que se llamaba trigueño. Se dice trigueño a la persona que tiene rasgos africanos o indígenas americanos, o sea, que presentan rasgos de mezcla étnicas manifestadas a ojos vistas por el color de piel (Coria, 1998, p. 59). El uso creciente de este término ha provocado una disminución de la población afro-argentina. Cuando a los individuos se les llamaban trigueño, era para evitar la suposición automática de origen africano. Habían conseguido pasar a una categoría intermedia, en la que también había algunas poblaciones europeas. La expresión trigueño surgió como un eufemismo para evitar que la gente respetable fuera etiquetada como negra. Muchos trigueños acabaron siendo aceptados por la sociedad como blancos. Esta es una de las formas en que la sociedad trata de fracturar a la población negra para hacerla desaparecer (Yao, 2002).

Algunos afro-argentinos respondieron a esta oportunidad para escapar de la condición de casta que habían sufrido durante décadas. Así, se distanciaron de su pasado africano adoptando la cultura y los refinamientos europeos favorecidos por la llamada sociedad blanca de Argentina. Tras la caída de Juan Manuel de Rosas, la comunidad afro-argentina intentó olvidar los duros años de la dictadura y el legado de los símbolos de apoyo al gobernador de las "Naciones". También abandonaron los descendientes africanos muchas actividades culturales ligadas a sus orígenes africanos en favor de su blanqueamiento.

Siguiendo a Binayán Carmona Narciso, la modernización de Argentina también ha supuesto el ascenso social de un pequeño sector del pueblo afro. Eso ha permitido ampliar las posibilidades de participación en la vida social y económica. Incluso ha favorecido cambios en el comportamiento de este, en sus gustos y hábitos (Binayán Carmona, 1980). Para marcar la diferencia entre afroargentinos, muchos descendientes de África seguían llamándose “la clase”. Por lo tanto, podemos decir que esta diferencia de clase entre los afrodescendientes fue una fuente de división.

Esta fractura fue criticada por periódicos de la época como La Juventud. Ella se atacó al exclusivismo de un club social Ilamado "La Esperanza Argentina", fundado por las familias afroargentinas más prósperas. Así, para que un trabajador normal les pague, este grupo exigía tarifas muy elevadas. Pero las contradicciones más profundas eran las que se mantenían en virtud de los problemas inherentes a su propia raza. Por ello, La Juventud defendió la asociación mutualista y acusó a La Broma de haber adoptado un discurso burgués para su comunidad. Esta división fue una de las principales causas del retardo y la situación molesta de los afro-argentinos (La Juventud, 1876). Un periódico de la época citado por Jean-Arsène Yao (2002) lo describió en estos términos: 
Causa pena, inspira tedio; y sobre todo, da vergüenza, el solo hecho de considerar y ver; que todas las colonias extranjeras residentes aquí en Sud América, aúnan sus elementos, formando Institutos de Beneficencia, Colegios, Centros Sociales, mientras nosotros somos los únicos que permanecemos aislados, sumidos como en un caos desempeñando a las mil maravillas el rol de parias en nuestra propia casa (Yao 2002).

\subsection{Insolidaridad del Estado}

Las operaciones hegemónicas del Estado argentino tuvieron históricamente propósito, construyendo un perfil étnico-racial del país como "blanco y europeo" según los dichos de Lea Geler (Geler, 2008a). Fue un proyecto de nación que ha recibido una mayor sustanciación y sistema desde las políticas estatales instauradas en el marco de la Generación del Ochenta (1880) como se llamaba. Así se impulsaron las alteridades afrodescendientes para reprimir o abandonar sus rasgos de etnicidad, de racialidad y reconvertirse integrando el repertorio de la nación del país, es decir, que la desaparición afro-argentina se basó en un mecanismo de etnicización de esta población que posibilitó un pasaje hacia lo "blanco-popular”. A esto Solomianski decía que:

(...) esta tendencia a la negación del componente poblacional afro-argentino (...) constituye uno más de los correlatos, efectos y procedimientos del principio constructivo que ha regido la configuración hegemónica del imaginario de la identidad nacional. Dicho principio constructivo puede sintetizarse como la operativa de blanqueamiento simbólico (“civilización", europeización) de un espacio "inferior", supuestamente "desértico" (dotado de objetos o "sujetos" degradados cuya idiosincrasia es la falta) y "anacrónico" (detenido o instalado en una etapa "pasada" del "itinerario evolutivo universal" del género humano") (Solomianski, 2003, pp. 24-25).

Pero la cuestión de las afiliaciones étnico-raciales no deseadas y su necesaria reconversión dentro del proyecto de un nuevo Estado-nación moderno no sólo estaba asociada a una reivindicación cultural e identitaria, sino también al hecho de que los prejuicios en cuestión estaban vinculados a la improductividad, la imposibilidad de progresar y la inadecuación a los valores de la ciudadanía. Geler, en este sentido sostiene que los periódicos afrodescendientes de finales del siglo XIX funcionaron como un "panóptico" de regeneración, aludiendo a que se censuraban y se denunciaban los comportamientos sociales "desviados" de los negros en favor del cambio social y facilitando la tarea del "Estado en construcción" de gestionar a los sujetos (Geler, 2008a, pp. 131-135). Y Domínguez, por su parte, establece una relación entre dicho proyecto y el hecho de que muchos de los intelectuales locales que teorizaron sobre la nación en la segunda mitad del siglo XIX compartían la ideología racial hegemónica de las universidades europeas donde hicieron sus estudios (Domínguez, 2004).

Concretamente, en el caso del contenido del currículo escolar, señala que "de esta forma, desde el siglo XIX, los alumnos han tenido acceso a este discurso, lo han consensuado y han co-construido representaciones de lo que era y sería la nación” (Geler, 2008a, p. 74). La educación pública, al igual que el servicio militar y el voto obligatorio, fue concebida "por el Estado y las clases dominantes como un instrumento legítimo para concretar la nacionalización de los inmigrantes europeo", es decir, para "argentinizar" (Domenech, 2005, p. 4).

Sin embargo, se privilegió la contribución europea y, en particular, la promoción de esta migración que tenía un objetivo político y económico definido en términos de un proyecto modernizador que incluía la reestructuración de la sociedad nacional. Por eso, Marquiegui dijo esto: 
Ellos son, ni más ni menos, o debían ser en el sentido alberdiano del término, los agentes necesarios de la modernización, llamados a completar la tarea inconclusa de la Revolución de Mayo modificando de raíz la estructura social de la nación de modo de generar las condiciones de posibilidad que hicieran viable el establecimiento de una verdadera y genuina democracia (Marquiegui, 1999, p. 40).

Según Alejandro Grimson, se ha instituido la asociación entre la argentinidad y la tradición europea de la inmigración, de modo que la "cultura nacional" ha sido concebida como el resultado de este proceso (Grimson, 1999). En este sentido, se puede afirmar que han proliferado actitudes y acciones en la sociedad, incluyendo los discursos de algunos líderes de partidos políticos, del gobierno, del sector sindical y de los medios de comunicación, que podrían ser clasificado como manifestaciones de xenofobia hacia estos grupos.

Sin embargo, para este mismo contexto histórico, Grimson señala el surgimiento de una redefinición de las políticas estatales en relación con el reconocimiento de las diversidades étnicas incluyendo la diversidad étnica (sobre todo la diversidad afro e indígena), junto con las políticas multiculturales a nivel global (Grimson, 2006).

\subsection{La identidad monocéntrica en Argentina}

Según Juan Carlos Tedesco, el gobierno argentino inició una transformación de su aparato nacional desde décadas, promoviendo un fuerte flujo de migratorio proveniente de Europa para facilitar una corriente nacionalista en el país. Esto cambiaría la fisonomía social y haría que el territorio fuera productivo haciendo desaparecer a los indios, pero sobre todo a los africanos. Para naturalizar esta operación, era necesario generar un discurso que ordenara la presencia y la voz del migrante europeo. Este discurso silenciaría las lenguas, las culturas, etc. (Tedesco, 1993). Así nació la Argentina blanca e hispana con la existencia en el Estado de pensamientos nacionalistas y ultraconservadoras cuyo discurso es rotundamente excluyente respeto a los africanos.

Siguiendo a Geler, podemos decir que la narrativa nacional argentina defendió en gran medida el principio de combinar razas para formar una sociedad multiétnica. Pero esto no era para las razas africanas e indígenas, sino a las europeas. Tomamos el caso de Brasil, por ejemplo. Allí el principio de la democracia racial afirmaba la conjunción entre las razas blanca, indígena y africana para el enriquecimiento de la cultura. Sin embargo, en Argentina, la abrumadora concepción de que "los argentinos descienden de los barcos" ha invisibilizado las versiones populares de nacionalidad atravesadas por pueblos que estaban presentes en las provincias del país. Ante esta idea, los investigadores se preguntaban cómo el movimiento afrodescendiente en Argentina superpondrá la afirmación de que ellos "también vinieron en los barcos" como personas esclavizadas (Geler, 2008).

Este nacionalismo monocéntrico logró acaparar durante muchas décadas el discurso de la nación estableciendo una jerarquía entre los grupos etno-culturales que componían el país. Siguiendo al INADI, más que una admisión histórica de la diversidad se reconoce ahora dentro del propio Estado argentino que "los modos iniciales de formación del Estado se estaban basando en rechazar de la diversidad de la herencia afro en América y en una centralización de la identidad sobre la base de la hispanidad católica" (Inadi, 2006, p. 99).

En cuanto a Mario Margulis y Marcelo Urresti, piensan que, por parte de los grupos más liberales de la época republicana, esta idea de abrir el país a la inmigración europea pretendía anular las raíces africanas y mestizas de la población argentina. Las políticas demográficas en este sentido estuvieron fuertemente influenciadas por la valoración de lo europeo, pero no sólo como modelo cultural, económico o político, sino también según el estado por la supuesta superioridad racial atribuida a los hombres de origen europeo (Margulis y Urresti, 1998). Esta era un aspecto 
eurocéntrico y este fue un proceso homogeneizador que se aplicó al concepto de "inasimilabilidad" (cosa que no se puede mezcla) a judíos, armenios, árabes, y gitanos y asumió que la identidad en Argentina era disconforme con los rasgos identitarios nuevos (Inadi, 2006).

En las políticas de asentamiento se produjeron varios acontecimientos históricos que tuvieron efecto a finales del siglo XIX, como el traslado de indios y africanos de las ciudades para que fueran invisibles. También los intelectuales considerados como inspiradores y constructores de la organización nacional de un país son los ideólogos que, hasta hoy, han configurado el imaginario nacional en términos de identidad. Entre los muchos intelectuales, podíamos encontrar a Alberdi, Sarmiento, Mitre, etc. En dos periódicos de la época, El Progreso y El Nacional citado por Fredy Rivera Vélez y Norma Alejandra Maluf, Sarmiento afirmaba que estos pueblos no sólo eran "incapaces de progresar", sino también "una repugnancia invencible" que no podía ser remediada, y promovía su exterminio como "providencial y útil, sublime y grandioso", añadiendo incluso que: "hay que exterminarlos sin perdonar siquiera a los pequeños, que ya tienen un odio instintivo al hombre civilizado" (El Progreso, 27/9/1844; El Nacional, 25/11/1876 citado por Fredy Rivera Vélez y Norma Alejandra Maluf, 2017, p. 159).

El proyecto de argentinización (difundir costumbre, cultura, idioma y todo lo relacionado con la Republica argentina) y homogeneización cultural según Grimson fue simultáneo a la de la construcción del Estado-nación moderno (1880-1930), e implicó que la etnicidad no se convirtiera en un lenguaje político notable. Según Briones y Segato citados por Grimson, a través de un proceso de desetnización, “la nación se constituyó en el gran antagonista de las minorías” y que era necesario liberarse de las categorías de origen para ejercer una ciudadanía plena (citado por Grimson, 2006, p. 3).

En Argentina, según Ratier, son las “cabecitas negras”, o dicho de otra manera "los negros”. Es una categorización racista producida en función de una operación política, ya que los obreros morenos provincianos se sintetizaron en la identidad política del peronismo. La categoría "cabecita negra" fue el matiz político que organizó el antagonismo casi racista entre Buenos Aires y los provincianos, donde "ser negro era ser peronista y viceversa" (Ratier, 1971, p. 13). Ser peronista se relaciona con el peronismo. Es un régimen político de carácter populista que fue implantado en Argentina por Juan Domingo Perón (militar y político argentino, 1895-1974) durante su presidencia del país, entre 1946 y 1955.

\subsection{La invisibilización del afro}

En esta parte queremos estudiar el campo de la invisibilidad afro en Argentina. Vamos a discutir en este apartado los discursos ligados a la presencia africana y sus aplicaciones en las políticas públicas nacionales dentro de un país autoreferenciado históricamente como blancos. Así consideramos el proceso de formación de identidad, de la alteridad y el lugar de los afroargentinos en el imaginario social hegemónico. De ahí resalta las continuaciones y las rupturas entre el proyecto de nación que fue pensada desde finales del siglo XIX hasta hoy. En el contexto del "resurgimiento" de la cuestión africanista en Argentina, nos interesa entonces problematizar los espacios institucionales que se fueron abriendo para repensar y trasladar el papel de los afrodescendientes como sujetos de la historia y de la cultura. Indagaremos las acciones y las disputas de los diferentes sujetos involucrados.

Podemos entender la invisibilización de la población afrodescendiente en el contexto argentino como una práctica discursiva y performática. Según contextos nacionales y regionales específicos se dio históricamente a partir de los proyectos hegemónicos nacionales luego de la abolición de la esclavitud. Stuart Hall dice que el discurso no es sólo un hecho social con efectos tan reales como cualquier otra práctica social. Pero es un potente dispositivo de articulación de la realidad nacional y cualquier otra práctica social. Según él, las prácticas sociales se encuentran apuntadas 
de variadas maneras en el discurso (Hall, 2010). Estas consideraciones nos sirven para criticar las que llamamos “afrologías”. Según Segato, la afrología se define como los discursos y las prácticas sociales que tiene relación con "lo afro", en el marco de una narración nacional de invisibilización de las alteridades (Segato, 2007).

Al igual que en los otros proyectos nacionales del continente americano, se encentra en Argentina según los dichos de Segato el mismo fenómeno de invisibilización de las diferencias a través del mestizaje que se presenta como una ideología hegemónica (Segato, 2007). Andrews apunta que la abolición de la esclavitud no significa libertad y conquista de igualdad por los esclavizados y sus descendientes, sino que significa la desaparición de todo lo que atañe a la población negra (Andrews, 1989, p. 12).

Por su parte, Alejandro Frigerio ha dicho que la práctica social de invisibilización manipulada en Argentina tuvo como consecuencia el blanqueamiento de la imagen de nación (Frigerio, 2010). En el plano real como en el imaginario, al igual que la de los pueblos originarios, la presencia negra negada en la historia y en la identidad nacional es una construcción nacional de un país que se ha fundado un ser latinoamericano a partir de la filiación privilegiada con Europa.

\begin{abstract}
...la creencia en una Argentina blanca y europea conforma un verdadero mito de origen de nuestra nacionalidad y opera por lo tanto en la actualidad, tanto en las grandes instituciones como en las pequeñas elecciones de la vida cotidiana (Martín, 2006, p. 206).
\end{abstract}

Digamos que en coincidencia con la inmigración de ultramar y con el avance del Estado sobre los territorios tradicionalmente ocupados por los pueblos indígenas, la idea de la desaparición de los afro-argentinos se afirmó rápidamente luego de 1880. Las transformaciones sociales que fueron guiadas por la concepción oportunista de la civilización llegaron en la difundida imagen de una Argentina blanca sin negros. Sigue diciendo Segato que esta operación de invisibilización de la diferencia responde al proyecto de formación de una "etnia argentina". Esta etnia se quedará dotada de una cultura única homogénea y esencializada, creando así una blanqueada nacional (Segato, 1999). Es interesante apuntar en este sentido el rol del mestizaje como proyecto político blanqueador del Estado Nacional Argentino luego de las independencias que sea a nivel fenotípico, biológico, cultural y social. A propósito de la desaparición numérica de los afro-argentinos basada en el discurso de la blanquedad argentina para invisibilizarles, George Reid Andrew es quien ha subrayado como la supuesta desaparición de los afro-argentinos, "uno de los enigmas intrigantes de la historia argentina", se debe leerla en relación con las transformaciones de categorías de razas empleadas en los censos del siglo XIX hasta su definitiva desaparición en el marco ideológico nacional (Andrews, 1989). Es así como se presenta el discurso invisibilizador de la comunidad negra en Argentina.

\title{
4. CONCLUSIÓN
}

La población afrodescendiente ha ocupado en la expansión colonial un lugar de sujeto, de explotación, de violencia, de fractura, de invisibilidad, de racismo y de discriminación en el Estado argentino que hicieron posible el establecimiento de grados de extinción éstos. Por lo que entendemos que es necesario abordar en toda su complejidad esta cuestión de los descendientes africanos buscando los posibles discursos que han servido de dialogo intercultural para fractura e invisibilizar la población negra. Consideramos a este discurso no solo como un concepto político, sino también como una estrategia discursiva para significar un modo de relación entre el Estado y la sociedad, y como una dimensión de la construcción de hegemonía. Al final, si se comunica el estadio de reconocimiento de las diferencias y avanzar esta sociedad intercultural argentina, digamos que resulta ser un proyecto prácticamente imposible de realizar, pero de vez en cuando parece ser el momento del horizonte más efectivo para sobrepasar las famosas palabras racismo, 
discriminación y del discurso intercultural. Eso es no solo para incluir a esas personas que fueron históricamente negados, sino para engrandecer a la sociedad. El desafío del Estado en un futuro próximo puede ser esto.

\section{REFERENCIAS}

Andrews, G. R. (1989). Los Afro-Argentinos de Buenos Aires. Ediciones de la Flor.

Binayán C. N. (1980). Pasado y permanencia de la negritud. Todo es Historia, 162, 66-72.

Coria, J. C. (1998). Pasado y presente de los negros en Buenos Aires. Editorial J. A. Roca

DOMENECH, E. E. (2005, julio 18-23). Políticas migratorias y estrategias de integración en Argentina: nuevas respuestas a viejos interrogantes. [Ponencia] XXV Conferencia Internacional de Población, Tours, Francia.

Domínguez, M. E. (2004). O "afro" entre os imigrantes em Buenos Aires: reflexões sobre as diferentas. (Disertación de Maestría) Universidad Federal de Santa Catarina, Brasil.

Edwards, B. H. (2001). The Uses of Diaspora. Social Text, 19(1), 45-73. https://doi.org/10.1215/01642472-191_66-45

Fredy, R. V., \& Norma, A. M. (2017). Después de la negación: el Estado argentino frente al racismo y la discriminación. Cuadernos del CENDES, 34(95), 155-182. http://saber.ucv.ve/ojs/index.php/rev_cc/ article/view/14187

Frigerio, A. (2008). De la 'desaparición' de los negros a la 'reaparición' de los afrodescendientes: comprendiendo la política de las identidades negras, las clasificaciones raciales y de su estudio en la Argentina. En G. Lechini (comp.), Los estudios afroamericanos y africanos en América Latina. Herencia, presencia y visiones del otro (pp. 117-14.) CLACSO.

Frigerio, A. (2009). Luis D'Elia y los negros: identificaciones raciales y de clase en sectores populares. Claroscuro. Revista del Centro de Estudios sobre Diversidad Cultural, 8(8), 13-43.

Geler, L. (2008). ¿‘Otros’argentinos? Afrodescendientes porteños y la construcción de la Nación argentina entre 1873 y 1882. (Tesis doctoral) Universitat de Barcelona.

Grimson, A. (1999). Relatos de la diferencia y la igualdad. Los bolivianos en Buenos Aires. Eudeba.

Grimson, A. (2006). Nuevas xenofobias, nuevas políticas étnicas en Argentina. En A. Grimson y E. Jelin (Comp.). Migraciones regionales hacia Argentina. Diferencia, desigualdad y derechos. (pp. 69-98). Prometeo.

Hall, S. (2010). Sin garantías. Trayectorias y problemáticas en estudios culturales. E. Restrepo, C. Walsh y V. Vich (Eds.). Envión Editores.

Helg, A. (1990). Race in Argentina and Cuba, 1880-1930: Theory, Policies and Popular Reaction. En R. Graham (Ed.) The Idea of Race in Latin America, 1870-1940. University of Texas Press.

Margulis, M., \& Marcelo U. (1998). La segregación negada. Cultura y discriminación social. Editorial Biblos.

Marquiegui, D. N. (1999). Del Crisol de Razas al Pluralismo Cultural: el Debate Historiográfico como Herramienta Orientadora de las Estrategias para la Enseñanza de la Historia. Clío \& Asociados. La historia enseñada, 4, 37-54. https://doi.org/10.14409/cya.v1i4.1544

Martín, A. (2006). Presencias ausentes. El legado africano a la cultura nacional. Temas de Patrimonio Cultural, $16,205-216$.

Plan Nacional contra la Discriminación (Inadi). (2006). La discriminación en Argentina. Diagnósticos y propuestas. República Argentina.

Ratier, H. (1971). El cabecita negra. Centro Editor de América Latina

Segato, R. L. (2007). La nación y sus otros: raza, etnicidad y diversidad religiosa en tiempos de políticas de la identidad. Prometeo Libros. 
Tedesco, J. C. (1993). Educación y sociedad en la Argentina (1880-1945). Solar

Vela, M. E. (2001). Historia y actualidad de los estudios afroargentinos y africanos en la Argentina. En D. Picotti (comp.) El negro en la Argentina. Presencia y negación. (pp. 49-62) Editores de América Latina

Yao, J. A. (2002). Negros en Argentina: integración e identidad Amnis, 2 https://doi.org/10.400o/amnis.183

\section{AUTOR}

Ibrahim Tuo. Doctor del Departamento de los Estudios Ibéricos y Latino-americanos Civilización Latinoamericana, Universidad Félix Houphouët Boigny Abidjan.

\section{Conflicto de intereses}

El autor declara que no existe conflicto de interés posible.

\section{Financiamiento}

No existió asistencia financiera de partes externas al presente artículo.

\section{Agradecimientos}

$\mathrm{N} / \mathrm{A}$ 